\title{
Veterinary Drugs Handling, Management and Supply Chain Assessment in Afar Pastoral Region of North East Ethiopia
}

\author{
Angesom Hadush Desta \\ College of Veterinary Medicine, Samara University, Samara, Ethiopia
}

Email address:

meryangieboy@gmail.com

\section{To cite this article:}

Angesom Hadush Desta. Veterinary Drugs Handling, Management and Supply Chain Assessment in Afar Pastoral Region of North East Ethiopia. American Journal of Bioscience and Bioengineering. Vol. 3, No. 6, 2015, pp. 142-148. doi: 10.11648/j.bio.20150306.11

\begin{abstract}
Animal medicines play an important role in the control and prevention of disease and animal suffering but have the potential to cause harm if not used properly. Veterinary drugs handling, management and supply chain assessment in Afar pastoral region of North east Ethiopia was done using structured questionnaire, key informants interview and focal group discussion. This survey showed that there is awareness gap on proper handling and management of veterinary drugs in the region that hamper its quality, safety and effectiveness. The effectiveness of drugs is damaged due to problems such as lack of awareness on how to handle and manage the drugs, lack of understanding of the potential effects of drug misuse and abuse and lack of required facilities. Training on safe handling and management of drugs $\left(X^{2}=21.23, \mathrm{P}=0.000\right)$ and professional level $\left(X^{2}=6.613\right.$, $\mathrm{P}=0.037$ ) had significant association with awareness on safe handling and management of veterinary drugs. However, According to the logistic regression analysis, it was only professional level $(\mathrm{OR}=0.03,95 \% \mathrm{CI}: 0.01-2.25, \mathrm{P}=0.027)$ that has statistically significant association with awareness of the professionals than the other variables considered during the analysis. There were many inappropriate practices and attitudes associated with improper drug handling and management issues in the professionals, awareness problems in the community and easy accessibility of the drugs in the black markets that can potentially affect the drug effectiveness. Generally, about $63.9 \%$ of the respondents showed that they had no enough knowledge on safe handling and management of drugs starting from acquisition to end user to assure the quality, safety and effectiveness of veterinary drugs. The major source of veterinary drug supply in Afar region were governmental source (65\%), private sources (5\%), nongovernmental organizations (10\%) and illegal sources (20\%). Therefore, continuous awareness creation works to the community, capacity building, training and upgrading programs to the professionals; encouraging privatization of veterinary drug supply and strict enforcement of drug control and administration regulation of the country is mandatory to avoid the aforementioned deep rooted problems in the region.
\end{abstract}

Keywords: Afar, Ethiopia, Management, Supply Chain, Veterinary Drugs

\section{Introduction}

Animal medicines play an important role in the control and prevention of disease and animal suffering but have the potential to cause harm if not used properly (VMD, 2012). Medicinal products, and starting materials used in the manufacture of medicinal products, should be stored and transported under conditions which ensure that their quality is maintained. Manufacturers' recommendations concerning storage temperatures should be observed and this may involve the use of specialized storage and transport facilities. Temperature-monitoring devices should be used to demonstrate compliance with the designated temperature ranges (Taylor, 2001).
Good warehousing and distribution practices require that storage areas for medicines should be maintained within acceptable temperature limits and that, where special storage conditions are specified by the manufacturer; these should be provided, checked and monitored. Measuring and monitoring equipment should be calibrated and checked at defined intervals. Medicinal products should be transported in such a way that they are not subjected to unacceptable degrees of heat and cold, and specialized means of transportation should be used where necessary (WHO, 2002).

The distribution chain is seldom simple and distribution systems may vary enormously. In its simplest form, the chain involves shipment direct from the manufacturer to the customer or end user. In its more complex form, the 
distribution chain may involve a number of storage and transit locations, including airports and docks, and a variety of transport facilities, including aircraft (Taylor, 2001).

Pharmacotherapy is one of the most important means of controlling livestock diseases, but it is possible only if livestock owners can afford to cover the cost of treatments. Cost of treatment is therefore, an important determinant of the usefulness of veterinary drugs. In Ethiopia, conventional veterinary services have been playing a paramount role in the control and prophylaxis of livestock diseases in the last three decades. However, they cannot yet deliver complete coverage in preventive and curative health care practices because of inadequate labor, logistical problems, an erratic supply of drugs, and the high cost of drugs and equipment. Consequently, the majority of those raising stock in rural areas especially are far from the site of veterinary stations, and those who have access to veterinary services may not be able to afford to pay for them. Additionally, reduced funding for animal disease control is an issue in Ethiopia and is likely to influence the incidence of some serious livestock diseases (Abebe, 2003, Sori et al., 2004; Admassu, 2010).Veterinary drugs handling and management problems, illegal drug smuggling and free charge drug supply are widely occurring events in Ethiopia especially in the pastoralist areas such as Afar region. Therefore, the general objective of this study was to assess the handling, management and supply chain of Veterinary drugs in Afar region of Northeast Ethiopia.

\section{Material and Methods}

\subsection{Description of Study Areas}

Afar regional state is located in the Great Rift Valley, comprising semi-arid rangeland in northeastern Ethiopia. According to regional estimates the livestock population of Afar is about 10.12 million TLU. The Afar Regional State has five administrative zones, which are further subdivided into 32 districts. Pastoralism and agro- pastoralism are the two major livelihood ways practiced in the region. The population of the region is estimated to be about 1.2 million of which $90 \%$ are pastoralists and 10\% agro-pastoral (CSA, 2007). The study was conducted in conveniently available private veterinary drug shop owners and public veterinary pharmacy attendants found in eighteen districts of Afar region.

\subsection{Study Population}

The population included in this study was private veterinary drug shop owners and public veterinary pharmacy attendants found in eighteen districts of Afar region, North east Ethiopia.

\subsection{Study Design}

A cross-sectional study was conducted to evaluate awareness, attitude and practices of the private veterinary drug shop owners and public veterinary pharmacy attendants towards veterinary drugs handling and management issues and to identify the veterinary drug supply chain in the region.

\subsection{Sampling Methods}

The study areas were selected purposively due to the convenient availability of private veterinary drug shop owners. The total sample size considered during the questionnaire survey was 36 animal health professionals who were actively working with veterinary drugs in which eighteen of them were private veterinary drug shop owners and the other eighteen were veterinary pharmacy attendants who work on public veterinary clinics. Moreover, animal attendants coming for animal treatment in veterinary clinics and animal health department experts in eighteen districts of Afar region were considered during the study time.

\subsection{Methods of Data Collection}

A separate and structured questionnaire was prepared and administered to the private veterinary drug shop owners and public veterinary pharmacy attendants to assess the knowledge, attitude and practice of the professionals towards veterinary drugs handling, management and supply chain issues. The questionnaire was pre- tested in the field to check for clarity and cultural acceptance of the ideas and relevant issues were incorporated in an open ended form. Verbal consent was obtained from the respondents after the objective of the study was explained to them before starting the interview. The questionnaire focused on veterinary drugs handling and management practices during acquisition, transportation, storage, dispensing and disposal of expired drugs. Focus group discussion was done with animal health professionals and animal attendants coming for animal treatment in veterinary clinic in each district. Moreover, Key informants interview was done to animal health department experts of each district in the study areas.

\subsection{Data Management and Statistical Analysis}

The data were summarized, cleaned, compiled, coded and stored in Microsoft Excel 2010 spread sheet and transferred to SPSS ${ }^{\circledR}$ Version 20 for statistical analysis. Descriptive and analytic statistics were computed using software SPSS ${ }^{\circledR}$ Version 20. Logistic regression analysis and cross tabulation were employed to see the association of risk factors with that of knowledge of the professionals about the safe handling and management of drugs. Odds ratio (OR) was used to indicate the degree of risk factor association with knowledge of the professionals about the safe handling and management of drugs signified by $95 \%$ confidence interval.

\subsection{Ethical Approval}

Verbal consent was obtained from the respondents after the objective of the study was explained to them before starting the interview.

\section{Results}

\subsection{Questionnaire Survey}

Awareness and practices of Animal health professionals 
towards safe handling and management of veterinary drugs was assessed using a structured questionnaire. A total of 36 respondents in which, 18 individuals from private veterinary drug shop owners and 18 from public veterinary pharmacy attendants were interviewed. Out of the 36 respondents, $28(77.8 \%)$ were male, $8(22.2 \%)$ were female and again $9(25.0 \%)$ of them were animal health technicians, $22(61.1 \%)$ were animal health assistants and $5(13.9 \%)$ were veterinary doctors. Out of the 36 respondents, it was only $13(36.1 \%)$ individuals who have better awareness on proper handling and management of veterinary drugs. According to the Chi square test, training on safe handling and management of drugs $\left(X^{2}=21.23, \mathrm{P}=0.000\right)$ and professional level $\left(X^{2}=6.613\right.$, $\mathrm{P}=0.037)$ had significant association with awareness on safe handling and management of veterinary drugs. However, According to the logistic regression analysis, it was only professional level $(\mathrm{OR}=0.03,95 \% \mathrm{CI}$ : $0.01-2.25, \mathrm{P}=0.027)$ that has statistically significant association with awareness of the professionals than the other variables considered during the analysis (Table 1).

Table 1. Logistic regression analysis of animal health professionals' awareness on safe handling and management of veterinary drugs in Afar region, North east Ethiopia.

\begin{tabular}{|c|c|c|c|c|c|c|}
\hline \multirow{2}{*}{ Category } & \multirow{2}{*}{ No. } & \multirow{2}{*}{ Awareness (\%) } & \multicolumn{2}{|c|}{ Cross tabs } & \multicolumn{2}{|l|}{ Multivariate } \\
\hline & & & $X^{2}$ & P value & $\mathrm{OR}^{\mathrm{a}}\left(95 \% \mathrm{CI}^{\mathrm{b})}\right.$ & P value \\
\hline \multicolumn{7}{|l|}{ Zone } \\
\hline Awsi Resu & 7 & $2(28.6)$ & & & & \\
\hline Kilebiti Resu & 6 & $2(33.4)$ & & & & \\
\hline Gebi Resu & 10 & $4(40.0)$ & 1.490 & 0.828 & $0.99(0.37-2.7)$ & 0.991 \\
\hline Fenti Resu & 5 & $1(20.0)$ & & & & \\
\hline Hari Resu & 8 & $4(50.0)$ & & & & \\
\hline \multicolumn{7}{|l|}{ Sex } \\
\hline Male & 28 & $10(35.7)$ & & & & \\
\hline Female & 8 & $3(37.5)$ & 0.009 & 0.926 & $0.134(0.01-5.27)$ & 0.284 \\
\hline \multicolumn{7}{|l|}{ Age } \\
\hline$<30$ & 11 & $3(27.3)$ & & & & \\
\hline $30-40$ & 15 & $4(26.7)$ & 3.426 & 0.180 & $0.62(0.04-9.10)$ & 0.728 \\
\hline$>40$ & 10 & $6(60.0)$ & & & & \\
\hline \multicolumn{7}{|l|}{ Professional level } \\
\hline $\mathrm{AHT}^{\mathrm{c}}$ & 9 & $1(11.1)$ & & & & \\
\hline $\mathrm{AHA}^{\mathrm{d}}$ & 22 & $8(36.4)$ & 6.613 & 0.037 & $0.03(0.01-2.25)$ & 0.027 \\
\hline $\mathrm{DVM}^{\mathrm{e}}$ & 5 & $4(80.0)$ & & & & \\
\hline \multicolumn{7}{|c|}{ Pharmaceutical experience } \\
\hline$<5$ & 17 & $6(35.3)$ & & & & \\
\hline $5-10$ & 10 & $3(30.0)$ & 0.438 & 0.803 & $1.03(0.06-16.12)$ & 0.985 \\
\hline$>10$ & 9 & $4(44.5)$ & & & & \\
\hline \multicolumn{7}{|l|}{ Type of business } \\
\hline Private & 18 & $7(38.9)$ & & & & \\
\hline Public & 18 & $6(33.4)$ & 0.120 & 0.729 & $5.76(0.12-23.32)$ & 0.374 \\
\hline \multicolumn{7}{|l|}{ Training } \\
\hline Yes & 9 & $9(100)$ & & & & \\
\hline No & 27 & $4(14.8)$ & 21.23 & 0.000 & $9.62(5.43-14.12)$ & 0.998 \\
\hline
\end{tabular}

$\mathrm{a}=$ Odds ratio $\mathrm{b}=$ Confidence interval; $\mathrm{c}=$ Animal health technician; $\mathrm{d}=$ Animal health assistant; $\mathrm{e}=$ Doctor of veterinary medicine

\subsection{Attitude and Practices}

Majority of the respondents $(91.7 \%)$ replied that they use public vehicle to transport drugs, only $38.9 \%$ of them store drugs according to manufacturer's direction and about $94.5 \%$ of them sell drugs without prescription (Table 2).

Table 2. Attitude and practices of animal health professionals on safe handling and management of veterinary drugs in Afar region, North east Ethiopia.

\begin{tabular}{lll}
\hline Questionnaire items & $\begin{array}{l}\text { Response } \\
\text { category }\end{array}$ & $\begin{array}{l}\text { No of } \\
\text { respondents (\%) }\end{array}$ \\
\hline $\begin{array}{l}\text { How do you buy drugs to your } \\
\text { shop? }\end{array}$ & Face to face & $32(88.9)$ \\
How do you transport drugs to your & Agent & $4(11.1)$ \\
shop? & Public transport & $33(91.7)$ \\
$\begin{array}{l}\text { Do you store drugs in your shop } \\
\text { according to manufacturer's }\end{array}$ & Yes & $3(8.3)$ \\
direction? & No & $14(38.9)$ \\
\hline
\end{tabular}

\begin{tabular}{lll}
\hline Questionnaire items & $\begin{array}{l}\text { Response } \\
\text { category }\end{array}$ & $\begin{array}{l}\text { No of } \\
\text { respondents (\%) }\end{array}$ \\
\hline Do you have a drug store in your & Yes & $20(55.6)$ \\
shop? & No & $16(44.4)$ \\
Do you arrange your shop in a & Yes & $25(69.5)$ \\
manageable way? & No & $11(30.5)$ \\
Have you ever made self inspection & No & $36(100)$ \\
and audit? & Yes & $34(94.5)$ \\
Do you sell drugs without & No & $2(5.5)$ \\
prescription? & Paper & $7(19.5)$ \\
What do you use while packaging & Plastic & $29(80.5)$ \\
drugs for selling to clients? & Yes & $36(100)$ \\
Do you advise end users on drug & Yes & $36(100)$ \\
handling and administration? & Yes & $11(30.6)$ \\
Do you treat animals by yourself? & No & $25(69.4)$ \\
Do you have a case book? & Yes & $20(55.5)$ \\
Do you complete treatment and & No & $16(44.5)$ \\
follow up animals that you treat? & Burning & $33(91.7)$ \\
How do you dispose expired & Burying & $3(8.3)$ \\
drugs? & &
\end{tabular}




\subsection{Awareness}

About $86.1 \%$ of the respondents had no acquisition form for drug transaction, $72.2 \%$ refer manufacturer's direction for use and about $63.9 \%$ had no enough knowledge on safe handling and management of drugs starting from acquisition to end user (Table 3).

Table 3. Awareness of animal health professionals on safe handling and management of veterinary drugs in Afar region, North east Ethiopia.

\begin{tabular}{|c|c|c|}
\hline Questionnaire items & Response category & $\begin{array}{l}\text { No of } \\
\text { respondents (\%) }\end{array}$ \\
\hline \multirow{2}{*}{$\begin{array}{l}\text { Know how about code of ethics } \\
\text { for pharmacists }\end{array}$} & Yes & $7(19.4)$ \\
\hline & No & $29(80.6)$ \\
\hline \multirow{4}{*}{$\begin{array}{l}\text { Knowledge on national } \\
\text { veterinary drugs regulation } \\
\text { Do you have an acquisition } \\
\text { form for drug transaction? }\end{array}$} & Yes & $33(91.7)$ \\
\hline & No & $3(8.3)$ \\
\hline & Yes & $5(13.9)$ \\
\hline & No & $31(86.1)$ \\
\hline \multirow{3}{*}{$\begin{array}{l}\text { What do you register in the } \\
\text { acquisition form? }\end{array}$} & Batch number & $2(40.0)$ \\
\hline & Quantity acquired & $5(100)$ \\
\hline & Address of supplier & $3(60.0)$ \\
\hline \multirow{3}{*}{$\begin{array}{l}\text { Do you know things that can } \\
\text { affect a drug during } \\
\text { transportation and storage? }\end{array}$} & Temperature & $36(100)$ \\
\hline & Humidity & $29(80.6)$ \\
\hline & Sunlight & $32(88.9)$ \\
\hline \multirow{2}{*}{$\begin{array}{l}\text { Do you know the importance of } \\
\text { drug packaging? }\end{array}$} & Containment & $36(100)$ \\
\hline & Protection & $30(83.4)$ \\
\hline \multirow{2}{*}{$\begin{array}{l}\text { Do you know the importance of } \\
\text { drug labeling? }\end{array}$} & Identification & $36(100)$ \\
\hline & Handling information & $28(77.8)$ \\
\hline \multirow{2}{*}{$\begin{array}{l}\text { Do you refer manufacturer's } \\
\text { direction to use? }\end{array}$} & Yes & $26(72.2)$ \\
\hline & No & $10(27.8)$ \\
\hline \multirow{2}{*}{$\begin{array}{l}\text { Do you refer drug leaflets and } \\
\text { handling manuals? }\end{array}$} & Yes & $23(63.9)$ \\
\hline & No & $13(36.1)$ \\
\hline \multirow{2}{*}{$\begin{array}{l}\text { Do you record drug expiration } \\
\text { dates? }\end{array}$} & Yes & $29(80.6)$ \\
\hline & No & $7(19.4)$ \\
\hline $\begin{array}{l}\text { Do you record drug withdrawal } \\
\text { periods? }\end{array}$ & No & $36(100)$ \\
\hline \multirow{2}{*}{$\begin{array}{l}\text { Do you label drug expiration } \\
\text { dates on packages/containers? }\end{array}$} & Yes & $21(58.3)$ \\
\hline & No & $15(41.7)$ \\
\hline \multirow{2}{*}{$\begin{array}{l}\text { Do you use expired drugs for } \\
\text { treatment for some time? }\end{array}$} & Yes & $22(61.1)$ \\
\hline & No & $14(38.9)$ \\
\hline \multirow{4}{*}{$\begin{array}{l}\text { For how much time do you use } \\
\text { expired drugs for treatment? } \\
\text { Do you have enough } \\
\text { knowledge on safe handling } \\
\text { and management of drugs } \\
\text { starting from acquisition to end } \\
\text { user? }\end{array}$} & One month & $15(68.2)$ \\
\hline & $>$ One month & $7(31.8)$ \\
\hline & Yes & $13(36.1)$ \\
\hline & No & $23(63.9)$ \\
\hline
\end{tabular}

\subsection{Veterinary Drug Supply Chain}

According to the key informants interview and focus group discussion, the major source of veterinary drug supply in Afar region were governmental source, private sources, local and international nongovernmental organizations and illegal sources. In addition, according to the proportional pilling result, around $65 \%$ of the veterinary drugs in the region were sourced from the government (Figure 1).

The veterinary drugs from governmental source reach to end users through distribution via regional pastoral agriculture and rural development office to district level agriculture offices and finally to veterinary clinics and animal health posts found in each district. The nongovernmental organizations working in this region provide veterinary drugs support to the region through different methods. Some of the NGOs donate veterinary drugs to the regional government or agriculture office but some other NGOs donate the drugs directly to districts after selecting by their own criteria and interest and sometimes especially in emergency cases and outbreak times the NGOs gives on field veterinary services particularly vaccination and deworming programs to the animals by themselves (Figure 2).

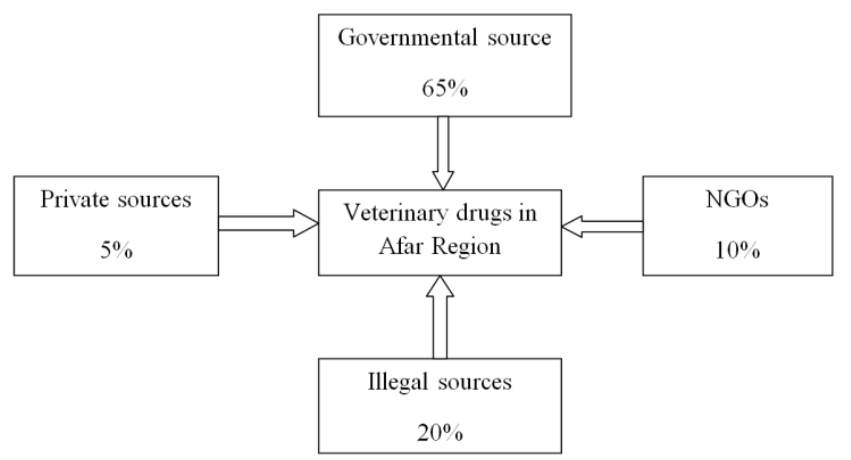

Figure 1. Source of Veterinary drugs in Afar region.

The private veterinary service actors in the region were mainly private veterinary drug shop owners in the town and community animal health workers in the rural areas. Both of these actors sell drugs to clients and give treatment to animals. The governmental, nongovernmental and private sources get the drugs from distributors in the capital city of the country, Addis Ababa and other neighboring towns such as Adama, Dessie, Kombolcha and Mekelle. The illegal drug sellers in local shops, boutiques, village markets and medical pharmacy shops get the veterinary drugs from retailers without any legal license and from black market inside and outside the country.

The veterinary drug supply chain starts from importers in Addis Ababa till the end users in the region (Figure 2).

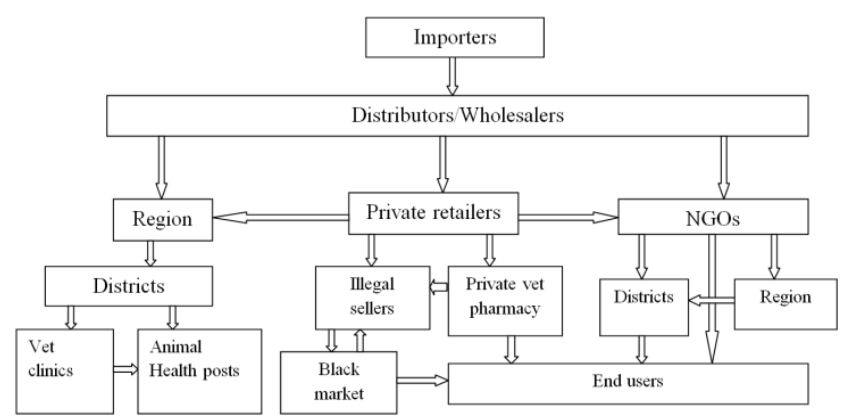

Figure 2. Map of veterinary drug supply chain in Afar region.

\section{Discussion}

The livelihood of the pastoral community is mainly depending on livestock production (Admassu, 2003; Zewdie, 2004). There are different types of animal diseases in these areas even diseases that can be transmitted to humans. However, the veterinary services and the amount of veterinary inputs mainly drugs is not equivalent with the animal population available (Sori et al., 2004; MOARD, 2010). Veterinary drug handling and management problems, illegal drug smuggling and free charge drug supply are widely 
occurring events in the pastoralist areas of Ethiopia such as Afar region. The effectiveness of these drugs is damaged due to problems such as lack of awareness on how to handle and manage the drugs, lack of understanding of the potential effects of drug misuse and abuse and lack of required facilities.

\subsection{Questionnaire Survey}

Awareness and practices of animal health professionals towards safe handling and management of veterinary drugs was assessed using a structured questionnaire. A total of 36 respondents in which, 18 individuals from private veterinary drug shop owners and 18 from public veterinary pharmacy attendants were interviewed. Out of the 36 respondents, 28 $(77.8 \%)$ were male, $8(22.2 \%)$ were female and again 9 $(25.0 \%)$ of them were animal health technicians, $22(61.1 \%)$ were animal health assistants and $5(13.9 \%)$ were veterinary doctors. Out of the 36 respondents, it was only $13(36.1 \%)$ individuals who have better awareness on proper handling and management of veterinary drugs. This survey showed that there is awareness gap on proper handling and management of veterinary drugs in the region that hamper its quality, safety and effectiveness. If the drugs are not handled and administered properly, there will be drug ineffectiveness that leads to high morbidity and mortality of animals that directly affects the life of the pastoralists. The other potential threat of this improper drug handling and administration is drug resistance development in which finally no drug will be left for treatment in the pastoral areas because the variety of drugs commonly used in these areas are very few.

According to the Chi square test, training on safe handling and management of drugs $\left(X^{2}=21.23, \mathrm{P}=0.000\right)$ and professional level $\left(X^{2}=6.613, \quad \mathrm{P}=0.037\right)$ had significant association with awareness on safe handling and management of veterinary drugs. This finding revealed that awareness creation training and upgrading educational level has a positive impact on reducing the knowledge gap of the professionals. However, According to the logistic regression analysis, it was only professional level $(\mathrm{OR}=0.03,95 \% \mathrm{CI}$ : $0.01-2.25, \quad \mathrm{P}=0.027)$ that has statistically significant association with awareness of the professionals than the other variables considered during the analysis. This showed that professional level is 0.03 times more probability of reducing knowledge gap than the other risk factors considered during the analysis.

\subsection{Attitude and Practices}

Majority of the respondents replied that they use public vehicle to transport drugs $(91.7 \%)$, do not store drugs according to manufacturer's direction (61.1\%), sell drugs without prescription $(94.5 \%)$ and all respondents do not make self inspection and audit (100\%). These findings showed that there are inappropriate practices and attitudes in the professionals that can potentially affect the drug effectiveness since these conditions collectively show improper drug handling and management issues. Public transport and storing drugs without referring the manufacturer's direction can expose veterinary drugs to sunlight, unadjusted temperature, humidity and other conditions including physical damage to the containers which disturbs the stability of the drugs.

The other most critical and unethical practice is selling drugs without prescription in which the sellers have no knowledge for what purpose the drug is going to be used. This condition facilitates the drug misuse and abuse, drug resistance and unexpected outcome in both animal and human health. This is because the purpose, dosage, method of administration, contra indication and other conditions of the drugs is not clear to the sellers and users unless it is accompanied through prescription. The pastoralists give under dosage of drugs on the basis to treat numerous animals at a time with the available amount of drug and on the other hand, they give over dosage on the basis to relieve animal pain within a short period of time. They believe that all types of drugs are functional and can be given to all types of animals at any time.

According to the focal group discussion, the pastoralists buy drugs without prescription from pharmacy and from black markets easily and they put it in the roof of their local house for long period of time and use it for treating their animals and also to treat themselves. They apply drugs such as oxytetracycline and penicillin to wounds and swellings in their body and take it orally for systemic infections. They wash their hair using ivermectin and apply it in their body to kill lice and fleas. The community believes that any drug that treats animal disease can treat human disease. This all are due to the knowledge gap and awareness problems in the community and easy accessibility of the drugs in the black markets. Moreover, all respondents $(100 \%)$ treat animals by themselves besides to selling drugs and all of them (100\%) advice end users how to handle and administer drugs. However, only $30.6 \%$ of them have case recording book and about 55.5\% complete prescribed treatment duration and follow up treated animals. This showed that the disease recording and documentation practice and monitoring system in the region is not satisfactory. Besides, majority of the respondents $(80.5 \%)$ use plastic while packaging drugs for selling to clients and about $91.7 \%$ of them dispose expired drugs by burning.

\subsection{Awareness}

Around $80.6 \%$ of the respondents told that they have never read about code of ethics for pharmacists because it is not available in compiled document in their office but majority of them $(91.7 \%)$ have good Knowledge on national veterinary drugs regulation. Only $13.9 \%$ of the respondents use acquisition form for drug transaction and they register mainly batch number, quantity acquired and address of supplier. Almost all respondents know that temperature, humidity and sunlight can affect a drug during transportation and storage; the importance of drug packaging as for containment and protection; and the importance of drug labeling as for identification and handling information. This finding revealed that the respondents have better awareness on the condition that can affect the drug effectiveness but they do not have the 
required facilities to implement it correctly. About $72.2 \%$ of the respondents refer manufacturer's direction for use, around $63.9 \%$ of them refer drug leaflets and handling manuals, around $80.6 \%$ of them record drug expiration dates and about $58.3 \%$ of them label drug expiration dates on packages/containers while selling. This finding showed that still there is a gap in achieving the required practice and attitude of proper handling and administration of drugs.

Moreover, all of the respondents $(100 \%)$ do not record drug withdrawal periods in which they did not advice end users about the potential effect of drug residue on public health. Around $61.1 \%$ of the respondents use expired drugs for treatment in which $68.2 \%$ of them use expired drugs for one month and around $31.8 \%$ of them for more than one month time. This condition is emanated from two important things in which one is due to drug supply shortage that the pharmacists not dare to dispose these expired drugs in the absence of enough supply. The other reason is there is a thinking that expired drugs can continue being functional for some time. However, this is wrong attitude as manufacturers are profitable organizations in which they put the maximum limit of functionality of drugs. Generally, about $63.9 \%$ of the respondents showed that they had no enough knowledge on safe handling and management of drugs starting from acquisition to end user to assure the quality, safety and effectiveness of veterinary drugs. This could be due to lack of continuous awareness creation training, limited capacity building and upgrading programs and low enforcement of veterinary drug control and administration rules and regulations in the region.

\subsection{Veterinary Drug Supply Chain}

According to the key informants interview and focus group discussion, the major source of veterinary drug supply in Afar region are governmental source $(65 \%)$, private sources $(5 \%)$, local and international nongovernmental organizations (10\%) and illegal sources (20\%). According to this proportional pilling result, the drug supply in the region was dominated by the government while the private source supply is insignificant and there was a considerable illegal drug sources in the region.

The veterinary drugs from governmental source reach to end users through distribution via regional agriculture office to district level agriculture offices and finally to veterinary clinics and animal health posts found in each district. The nongovernmental organizations working in this region provide veterinary drugs support to the region through different methods. Some of the NGOs donate veterinary drugs to the regional government or agriculture office but some other NGOs donate the drugs directly to districts after selecting by their own criteria and interest and sometimes especially in emergency cases and outbreak times the NGOs gives on field veterinary services particularly vaccination and deworming programs to the animals by themselves. This condition cannot create sustainable change in the quality veterinary service delivery system since it is not done on strategic way and it does not address the remote areas as it depends on the interest of the projects.

The private veterinary service actors in the region were mainly private veterinary drug shop owners in the town and community animal health workers in the rural areas. Both of these actors sell drugs to clients and give treatment to animals. The veterinary drug supply chain starts from importers in Addis Ababa till the end users in the region. The governmental, nongovernmental and private sources get the drugs from distributors in the capital city of the country, Addis Ababa and other neighboring towns such as Adama, Dessie, Kombolcha and Mekelle. The illegal drug sellers in local shops, boutiques, village markets and medical pharmacy shops get the veterinary drugs from retailers without any legal license and from black market inside and outside the country.

These illegal actors sell veterinary drugs together with vegetables in local markets called 'gulit', inside local shops called 'sheketa sheket suk' together with substances used for cooking, in boutiques together with clothing and inside medical pharmacy shops without any legal permission. Diazinon, oxytetracycline, ivermectin and albendazole are the main drugs that can be found from such illegal sources. This condition discourages the legal drug sellers since the drug is easily accessible everywhere and of low price when compared with the licensed sellers. This condition affects the effectiveness of the drugs in which drug resistance can be developed and animal morbidity and mortality will be increased in one way and the other.

\section{Conclusion}

This survey showed that there was knowledge gap on proper handling and management of veterinary drugs in the region that affects its quality, safety and effectiveness. The effectiveness of drugs is damaged due to problems such as lack of awareness on how to handle and manage the drugs, lack of understanding of the potential effects of drug misuse and abuse and lack of required facilities. Training and professional level were the major risk factors that affect awareness on safe handling and management of veterinary drugs. There were many inappropriate practices and attitudes associated with improper drug handling and management issues in the professionals, awareness problems in the community and easy accessibility of the drugs in the black markets that could potentially affect the drug effectiveness. The major source of veterinary drug supply in Afar region was governmental source, private sources, nongovernmental organizations and illegal sources. The drug supply in the region was dominated by the government while the private source supply was insignificant and there was a considerable illegal drug sources in the region. Therefore, continuous awareness creation works to the community, capacity building, training and upgrading programs to the professionals; encouraging privatization of veterinary drug supply and strict enforcement of drug control and administration regulation of the country is mandatory to avoid the aforementioned deep rooted problems in the region. 


\section{Acknowledgements}

The Author is thankful to the respondents and pastoral agricultural office staffs for their genuine cooperation and provision of adequate information during the study time.

\section{References}

[1] Abebe G. (2003): Community-based animal health services delivery in Ethiopia. Experiences and the way forward on community-based animal health service delivery in Ethiopia. Proceedings of a workshop held in Addis Ababa, Ethiopia.

[2] Admassu, B. (2003): Primary Animal Health Care in Ethiopia: The experience so far Veterinary Field Officer Community-based Animal Health and Participatory Epidemiology unit AU/IBAR/CAPE Pp 1-13.

[3] Admassu, B. (2010): History of Community Animal Health Service Delivery: Current Scenario and Significance of Community Animal Health Network and Its Expected Outcomes. Proceeding of the CAHNET-Ethiopia Launching Work Shop Held at Ghion Hotel, Addis Ababa, $15^{\text {th }}$ April 2010, Ethiopia. Pp 14-25.

[4] AVA (Australian Veterinary Association), 2005: Guidelines for Prescribing, Authorizing and Dispensing Veterinary Medicines. Version 1.0, Kingston ACT 2604, Australia.www.ava.com.au. Accessed on 02/02/2015.

[5] CSA (Central Statistical Agency) (2007): Human and animal population census in Afar region. Addis Ababa, Ethiopia.
[6] MOARD (2010): Federal Democratic Republic of Ethiopia Ministry of Agriculture and Rural Development Country Position Regional Policy Framework on Animal Health, for Trade and Poverty Reduction Addis Ababa, January 2010. P. 11.

[7] Sori, T., Bekana, M., Adugna, G. and Kelbessa, E. (2004): Medicinal Plant in the Ethno veterinary practices of Borana Pastoralists, Southern Ethiopia. International journal of Applied Research in Veterinary Medicine, 2:220-225.

[8] Taylor, J. (2001): Recommendations on the control and monitoring of storage and transportation temperatures of medicinal products. The Pharmaceutical Journal, 267:128-131.

[9] VMD (Veterinary Medicine Directorate) (2012): Assuring the Safety, Quality and Efficacy of Veterinary Medicines. Code of practice on the responsible use of animal medicine in the farm, Surrey, UK. www.vmd.defra.gov.uk. Accessed on 05/11/2014.

[10] WHO (World Health Organization), (2002): Guidelines on packaging for pharmaceutical products. Technical Report Series, No. 902, Geneva, Switzerland. Pp. 121-145. www.ava.com.auAccessed on 01/02/2015.

[11] Zewdie, S. (2004): Animal Health Services Delivery in Ethiopia. Proceedings of the $18^{\text {th }}$ Annual Conference of the Ethiopian Veterinary Association (EVA), held in Addis Ababa, June 9-10, 2004, Ethiopia, Pp 51-55. 